\title{
Research on the Guidance of Sports System Based on the Big Data Technology
}

\author{
Wei Liu \\ Xi'an University of science and technology, Xi'an 710000, China \\ aawei@163.com
}

Keywords: Guidance and training mechanism, Social sports, National fitness, Running and service system

\begin{abstract}
The study analyzed the nature and features of China civilian physique policies implementation, and held that implementation of sport-for-all policy is a dynamic process converting the policy objective into reality, which includes a series of activities and behaviors pushing forward the implementation of policy. The implementation of sport-for-all policy in China is characterized not only by the general features in public policy implementation, but also by the specific ones in itself, and this determines the complexity of implementation process of sport-for-all policy and the enormous difficulty of implementation behaviors. The study put forward that the effective implementation of sport-for-all policy is influenced by the policy itself, the resources, the implementing parties, the targeted group, and the policy environment as well. Secondly, from the perspectives of behavior analysis and organization analysis, by scrutinizing the behavior features and the organization effectiveness of 3 stages of implementing scheme planning, resource preparing and deploying, and execution methods selecting the study explored the implementing results and brought out improving suggestions.
\end{abstract}

\section{Introduction}

Society wouldn't make any progress without the high-quality laborers, whereas the improvement of civilian's fitness is the physical foundation for all-rounded qualities of laborers. Therefore, building up the civilian physique reflects the objective requirement of social development in China. In recent years, China has attached more importance to the development of sport for all, and issued a series of policies and measures. As the achievement of policy objectives largely relies on the implementation process of policy, the inevitable choices of developing sport-for-all in China is to intensify the effective implementation of sport for all policy and to improve the execution effectiveness of government [1].

Up till now, most of the research and study on sport policies are focused far more on the results than on the process. In this dissertation, by means of such research methods as literatures, interview, questionnaire, logical analysis, the study discussed the characteristics and execution deviation of sport for all policy in each stage have been explored in a viewing to providing the suggestion for improving the effectiveness of policy execution. It has been well recognized and the common choices for the human beings that it is necessary to implement the human-centered social development strategy in the current modern society. Consequently constructing and consummating sport service system has been seen as an important research topic for building a well-off society in an all-round way and creating a harmonious society [2].

Currently, the background to promote the development of China's social sports instructors mainly lies in the unceasingly changing social and economic structures, which hence makes social sports constantly achieve development, and the social needs on sports instructions climb slowly as well. It can be said that the traditional mass sports have developed into social sports, because people's entertainment time gradually grows along with the high improvement of their material life, setting up a solid foundation for the broad masses to enhance the life quality. At the mean time, modern civil diseases are subsequently prevalent due to the factors such as the lack of exercises and over-great work pressures [3]. Therefore, a spontaneous mass sports upsurge quickly sparks and well develops, 
aiming to pursue personal health and relieve pressures. Nowadays, many countries formulate files on the promotion of rapid mass sports development, and reinforces the rules and guidance for the development. With the deepening of social sports, the requirements of common people on the scientific fitness and the improvement of sports activities effects are increasingly higher. Concerning about this reality of social sports, pushing forward the construction of China's social sports instructors has become a problem that people pay close attention to very much [4].

\section{The Basic Problems on the Forming Process of Social Sports Guidance}

Since the 1990s, sports has become a crucial part of social activities because China's socialist market economy has been established, and also gradually participates in the market allocation of social resources under the influence and driving of market economy, continuously tending to socialization, commercialization and marketization developments. Therefore, it is said that China's sports have transformed from social welfare to social consumption. Under the promotion of market economy, there are a large number of profit-making sports places to emerge in society, and the number of personnel engaging in such a profit-making physical fitness instruction job increases remarkably as well, so a working group based on physical fitness instruction are in fact expanding. With the exacerbation of competition, however, the requirements of market on physical fitness instructors prove to be higher and higher. As a result, the call for professional and industrial management on such a sort of personnel tends to be louder and louder. A new occupation in social sports instruction emerges speedily. In 1998, the occupation social sports instructor was listed into China's national occupational classification recognized the state. In 2001, the Ministry of Labor and Social Security promulgated "Social Sports Instructor National Occupation Standard", beginning to carry out occupational identification and standardized management on the personnel in this industry. Since then, the occupation social sports instructor gains a substantial development in China.

As China very late issued the social sports instructor system, both theoretical studies and practical discussions are quite deficient. In recent years, General Administration of Sport of China organized social sports experts to conduct overall investigations whose result indicated that the number of China's social sports instructors was not too many as a whole, the grading number and ratio do not mutually coordinate enough, and also there are series of problems in age, educational background and management. The construction of China's social sports instructors group still requires a longer course. Now, it is analyzed as the following: (1) The social background for social sports instructors emergence: China's social sports instructors emerged from mass' spontaneous exercises mainly based on the improvement of mass' life quality, and mass sports return to community and then community sports rise with the emergence of considerable commercial sports and the changes of social structure. Due to this large tide of social changes, social sports instructors emerged to adapt to the development of new social situation. (2) The current actual situation of China's social sports instructors: The ratio of social sports instructors at all levels in China does not cooperate in harmony, there is a unbalance between instructors' overall number and the development scales of both China's total population and the urban and rural sports instruction stations, and moreover the balances among provinces and cities, the western and eastern, and all minority nationality regions are also enough. Thus, the overall development of social sports instructors group encounters unbalance. (3) Social sports instructor's future development tendency: Presently, China's social sports instructors are still in the initial development stage. In view of the continuously rising and development of mass sports, people started to take part in various sports activities, and hence the establishment and training of social sport instructor system and the institutional and scientific management will certainly become the future development tendency of social sports instructors. Therefore, it is imperative to strengthen the research on social sports instructors in depth, allowing social sports development and society development mutually coordinated with each other.

\section{The Training Strategies of China's Social Sports Guidance and Training Mechanism}


First, the most important factor to influence social sports instructors lies in the economic development level Sports activities have to coordinate with economic development. Not only will economy directly influence the overall development level of social sports, and it also impacts the development scales and speed of China's social sports instructors. Social and government functional departments are short of the abilities to support social sports, and are hard to offer social sports instructors with adequate material foundation. Government functional departments will always give priority to the development of competitive sports with a few of funds on social sports, even though there are quite abundant funds. Therefore, one of the major reasons to influence the rapid development of social sports instructors is a few of financial investment. Second, the recognition of social sports instructors on their own physical fitness functions remains inadequate, which mainly relies on their educational backgrounds. What's more, quite many social sports instructors lack the recognition on all social functions of sports. Finally, their professional theories are relatively insufficient. Now, many social sports instructors in China still don't know enough about sports professional theoretical knowledge. A majority of them has insufficient understanding of sports professional theoretical knowledge, which directly impacts the initiative and activeness of group activities. Furthermore, the abilities of many social sports instructors to do demonstration and explanation are relatively poor, hard to clear up technologies, so it influences the social sports activities to be effectively launched.

As China gets continuous developments in all the as peas of society, politic, economy and culture and the national fitness program has taken deeper root in people, the broad masses of the people have gradually recognized that social sports can promote people's health and improve the quality of life; the number of the people joining social sports is stepping up; various fitness places with a mass character spring up constantly; the sports for leisure exercise, the old and the disabled rise abruptly as well; and social sports instructors have become the significant professional talents in mass sports. The physical education programs in higher educational schools should seize the opportunity to take full advantage of their own strengths, such as adding some courses to design social sports instruction in the physical education program courses offering, and thereby can cultivate high-quality social sports instruction talents for the national fitness. This can not only expand the employment of the physical education majors at higher educational schools, but also can cultivate the sports instruction talents adaptable to the sports needs of different areas and people with plans and gradual steps for the booming development of the nationwide fitness sports.

Based on the development features of social sports in China and the actual needs of exercising people, social sports instructors can be divided into three types: gymnasium, leisure and entertainment and traditional national sports, in which it is especially necessary to strengthen the construction of traditional national sports instructors China, as an ancient civilization country owing five thousand years of brilliant histories and splendid cultures, has rich and colorful physical fitness sports not only with high exercising values and also easy to be developed. For example, Chinese shadow boxing and Yangko not merely promote cultures, but also resolve the problems that the sports fields and equipments for people are insufficient, and meanwhile cover the social physical education at all levels. Then, the instructions can proceed in accordance with the differences among exercisers. In addition, through the cross of different types and different levels of sports, the all-round social sports instruction pattern in an all-round way can come into shape gradually.

Currently, the surviving space for social sports instructors at China's labor market is rather small, which still do not really melt into talent network. Sports administrative departments should intensify the promotion for social sports instructors, making the profession a good job that everyone admires. Market mechanism is employed to popularize this new profession besides many positive publicity means and the implementation of occupational admittance system. It is necessary to gradually construct the occupational identification market for social sports instructors, convert the previous obsolete mode under which the training, evaluation and authentication of social sports instructors are controlled completely, and attract all fitness companies to the development of the social sports instruction markets with might and main, and gradually popularize this new profession into all social corners through the market model. 


\section{Suggestions for Improving the Status of Guidance and Training Mechanism of Social Sports}

The service system of the national fitness can be seen as a kind of integration including all the software and hardware techniques that were adopted in order to ensure the main body of the service system can fulfill the needs of its customers. The service system of the national fitness consists of the basic environment and condition, the main-body provider of the spot fitness service, and the main-body demander of the sport fitness service, which can be characterized as three main features, such as multiple organization patterns, the perfect review system of the national physical fitness, and the effective legal protection system, existing as the public service pattern and marketing service model. The main-body demanders of the service system of the national fitness are recognized as a complex that includes national, social, and individual need. In the context of the Chinese transitional society transferred from industrialization to marketing, the factor of social class plays a very important role in influencing behaviors, value points, and needs of sports. The satisfaction of the service system for the national fitness is relatively low. Moreover the degree of satisfaction is different in different social groups.

The main-body providers can be seen as the amount of varieties of sport fitness service which is offered by the main-body providers, Public sector. The public product of sport fitness service characterize as multi-facet. Central government provides sustaining system, knowledge system of sport fitness service for all over the country. Local government provides field, facilities and information of sport for the local resident. Nonprofit organization provides instruct, activity and some other sport service. As to each enterprise providing the sport fitness service, the service must be implemented in every procedure. The procedure of providing service can be seen as the outcome of the coincidence of different components, including marketing system, running system, human resource system, fitness service program, transferring systematic design and service delivery system.

\section{Conclusions}

In conclusion, as China's social productivity develops speedily and people's life quality rise gradually with increasingly more spare time, the pursuit for personal physical and psychological health becomes higher and higher, which builds up people's health consciousness to be highly intensive. It can be said that the unceasing development of national fitness sports puts forward higher requirements on the expansion of social sports instructor group. By integrating the current situation of China's social sports instructors, it is imperative to constantly deepen reform, actively adjust tactics, optimize the effective configuration of all systems, promote social sports instructors to fully play their own strengths and undertake the important responsibilities for social sports development on their own initiative, endlessly strength and improve the construction of China's social sports instructor system, and create a professional social sports instructors group with plentiful high-quality personnel

\section{Acknowledgements}

2014 Social Science Fund Project of Hebei Province; 2013 Shijiazhuang Municipal Science and Technology Research and Development Mentoring Program;

\section{References}

[1] Sun Peichu. Investigation on Social Sports Instructor Group Bulletin of Sport Science\&Technology, 2005 (8)

[2] Dai Jianhui\&Yu Chonggan. Investigation and Analysis on the Application Situation of China's Social Sports Instructors, Journal of Shanghai University of Sport, 2005 (9)

[3] Ding Limin. Sociology on the Current Situation of China's Social Sports Instructors. Journal of Shandong Institute of Physical Education and Sports, 2006 (8) 
[4] Yu Shanxu. Discussion on the Improvement of Relevant Key Problems in China's Social Sports Instructors System. Journal of Tianjin Institute of Physical Education, 2007 (5) 